\title{
Disorders of Acid-Base Balance: New Perspectives
}

\author{
Julian L. Seifter ${ }^{a}$ Hsin-Yun Chang ${ }^{b}$ \\ ${ }^{a}$ Renal Division, Department of Medicine, Brigham and Women's Hospital, Harvard Medical School, Boston, MA, \\ USA; ${ }^{b}$ Kaohsiung Medical University Hospital, Kaohsiung, Taiwan, ROC
}

\section{Keywords}

Acid-base balance · Physiologic compensations - Electrolyte disorders

\begin{abstract}
Background: Disorders of acid-base involve the complex interplay of many organ systems including brain, lungs, kidney, and liver. Compensations for acid-base disturbances within the brain are more complete, while limitations of compensations are more apparent for most systemic disorders. However, some of the limitations on compensations are necessary to survival, in that preservation of oxygenation, energy balance, cognition, electrolyte, and fluid balance are connected mechanistically. Summary: This review aims to give new and comprehensive perspective on understanding acid-base balance and identifying associated disorders. All metabolic acid-base disorders can be approached in the context of the relative losses or gains of electrolytes or a change in the anion gap in body fluids. Acid-base and electrolyte balance are connected not only at the cellular level but also in daily clinical practice. Urine chemistry is essential to understanding electrolyte excretion and renal compensations. Key Messages: Many constructs are helpful to understand acid-base, but these models are not mutually exclu-
\end{abstract}

sive. Electroneutrality and the close interconnection between electrolyte and acid-base balance are important concepts to apply in acid-base diagnoses. All models have complexity and shortcuts that can help in practice. There is no reason to dismiss any of the present constructs, and there is benefit in a combined approach.

c) 2016 S. Karger AG, Basel

\section{Introduction}

The hydrogen ion concentration of body fluids is maintained within a narrow range for purposes of regulating normal metabolic and enzymatic processes and critical functions such as fertilization, growth, cell volume regulation, and protein synthesis. Since the $\left[\mathrm{H}^{+}\right]$is in nanomolar concentrations, compared to bicarbonate in millimolar amounts, it is clear that the $\left[\mathrm{H}^{+}\right]$is involved in many reactions. Hydrogen is in equilibrium with water which exists in a concentration of $55.5 \mathrm{M}$; with carbon dioxide, a gas exhaled by the lungs (an open buffering system), with proteins, weak acids like hydrogen phosphate, and is involved in many oxidation reduction reactions, and adenosine triphosphate (ATP) synthesis. It is usual to express acidity in logarithmic form as the $\mathrm{pH}$, defined

\section{KARGER}

E-Mail karger@karger.com

www.karger.com/kdd
C 2016 S. Karger AG, Base

2296-9381/16/0024-0170\$39.50/0
Julian L. Seifter, MD

Renal Division, Department of Medicine

Brigham and Women's Hospital

75 Francis Street, MRB-4, Boston, MA 02115 (USA)

E-Mail jseifter@ partners.org 
as the $\log 1 /\left[\mathrm{H}^{+}\right]$. Because most cells in the body are electronegative to the extracellular space, the equilibrium $\mathrm{pH}$ within cells is lower than the external fluid. Though intracellular $\mathrm{pH}$ is more acidic than extracellular, most cells have available mechanisms to prevent $\mathrm{pH}$ from excessive increases or decreases. It is interesting that the same transporters, available to all cells to control their own $\mathrm{pH}$, are used by the kidney tubules to eliminate acid into the urine. The extracellular $\mathrm{pH}$ is normally in the range of 7.35-7.45.

One source of acid in the body is cellular production of carbonic acid, consisting of carbon dioxide and water, in equimolar quantities; on average, this amounts to about 20 moles per day, accounting for approximately $400 \mathrm{ml}$ of water. Carbon dioxide is called volatile acid because it is eliminated by alveolar ventilation. Its source is the oxidized carbon skeleton of carbohydrates, ketoacids, fat, and amino acids. Another class of cellular acid, known as nonvolatile or fixed acids, consists of sulfates and phosphates from protein, phospholipid, and nucleic acid metabolism, as well as inorganic sources such as chloride salts. Quantitatively, the fixed acids are produced on the order of $1 \mathrm{mEq}$ of hydrogen per kg body weight per day. Though these acids are comparatively small in amount, excretion must be in an aqueous medium, mainly urine. For that final process to be effective in eliminating 50-100 $\mathrm{mEq}$ of $\mathrm{H}^{+}$a day, there must be buffers in the urine to pick up the hydrogen. An acid urine itself is not enough. For example, $1 \mathrm{~L}$ of urine at maximal urine acidity of $\mathrm{pH} 5$ contains only $10 \mu \mathrm{mol}$ of hydrogen.

The impact of diet on acid-base production is determined by whether it is acid ash or alkaline ash, the former containing a predominance of sulfur, phosphorus, or chloride upon complete combustion, the latter an abundance of sodium, potassium, calcium and magnesium. Therefore, ingestion of sodium or potassium lactate, citrate, acetate, or bicarbonate, will, after complete metabolism of the organic anions, yield an alkaline load.

Maintenance of normal steady state acid-base balance requires that all acid produced equals all acid excreted. The renal clearance of acid anions (and reciprocally the production of replacement bicarbonate consumed by the acid produced) depends on full reabsorption of filtered bicarbonate and then a formation of a buffered urine containing ammonia produced by the kidney and excreted as ammonium, with filtered phosphate and chloride. Alveolar ventilation is the analogous mechanism for carbon dioxide clearance. An inequality of production and elimination for carbon dioxide results in respiratory disorders, and for fixed acids, metabolic disorders. The extent of the deviation of $\mathrm{pH}$ from normal depends on the ability to come to a new steady state of input equals output, at a new abnormal level of $\mathrm{pCO}_{2}$ for respiratory disturbances and of bicarbonate concentration for metabolic disorders. However, a steady-state bicarbonate concentration cannot rule out persistent net acid retention because bicarbonate lost from bone mineral breakdown in acidosis enters the circulation. As will be discussed, body compensations are also important in establishing the new steady state $\mathrm{pH}$ in disease.

Although it is customary to assess acid-base disorders by its reflection in the extracellular fluid rather than the intracellular space, such practice is an oversimplification and also a potential source of error, since so many $\mathrm{pH}$ dependent metabolic processes and functions relate to intracellular electrolytes and acid-base. Intracellular $\mathrm{pH}$ measurements, which may vary between cell types, are not available to the clinician and are consequently neglected or inferred from peripheral blood.

\section{The Brain and Acid-Base Balance}

An area that is often neglected in the discussion of clinical acid-base disturbances is the regulation of hydrogen ion concentrations of brain cells and surrounding interstitial fluid. Brain $\mathrm{pH}$ as reflected by the cerebral spinal fluid is critically important for central nervous system (CNS) function and differs from peripheral $\mathrm{pH}$ regulation in that it is more precisely controlled within a narrow range by unique cellular mechanisms of adaptation [1-3]. These mechanisms allow the brain to compensate back to near-normal $\mathrm{pH}$ in each of the primary disturbances: metabolic acidosis and alkalosis, and respiratory acidosis and alkalosis. Acid-base imbalance in brain disease, such as stroke, may be reflected in peripheral blood analysis. Correction of systemic $\mathrm{pH}$ in those settings may disrupt important brain compensations [4]

The brain is also a vital organ in the regulation of body $\mathrm{pH}$ in cases of systemic disorders. The connection of sensory input to the CNS depends on chemosensors in the aortic arch and carotid body, with neural inputs to the CNS and subsequent outgoing neural signals involved in regulation of alveolar ventilation. Acidification of the brain interstitial fluid results in increased ventilation, whereas medullary interstitial fluid alkalization results in decreased ventilation [5]. In addition, due to different permeabilities of the blood brain barrier for carbon dioxide, hydrogen ion, and bicarbonate, movement of these species into the CNS, each with a different time course, 
results in nonsteady state transitional changes in $\mathrm{pH}$ of the CNS. These transitions are at times paradoxical to the $\mathrm{pH}$ of the peripheral blood [6].

One example of the disequilibrium between peripheral and brain $\mathrm{pH}$ occurs when sodium bicarbonate is given to a patient to correct metabolic acidosis. There may be a paradoxical acidification of the brain, as carbon dioxide formed from the infused bicarbonate is more diffusible into the brain substance than bicarbonate anion [7]. The acidification of the brain interstitial fluid will lead to hyperventilation, causing systemic respiratory alkalosis, despite administration of alkalinizing bicarbonate to the extracellular fluid. It is also important to the intensivist to be aware of any intracerebral mass or hyponatremia before inducing permissive hypercapnia, since any mass effect or cerebral edema could be additive to the cerebral swelling that accompanies acidosis in the brain and result in herniation [8].

Regulation of $\mathrm{pH}$ in the brain involves lactate production in alkalosis. The oxyhemoglobin dissociation curve dictates decreased oxygen delivery to cells during metabolic alkalosis, even with decreased cerebral perfusion due to vasoconstriction in acute alkalemia. Accordingly, more lactate is produced through anaerobic glycolysis. The rate-limiting $\mathrm{pH}$-sensitive glycolytic enzyme phosphofructokinase I stimulates glycolysis at high intracellular $\mathrm{pH}$, thereby forming more lactate. A unique mechanism that the brain uses to protect its own $\mathrm{pH}$ during acidosis involves conversion of glutamine to glutamate, a process that liberates ammonia, a proton acceptor, and therefore contributes to a $\mathrm{pH}$ increase [9].

\section{Roles of the Normal Lung and Kidney in Acid-Base Disturbances}

The accepted wisdom that the lungs compensate for metabolic disturbances and that the kidney compensates for pulmonary disturbances is only part of the truth, in that signals to the lung modulate control of ventilation in respiratory disorders and metabolic disorders require renal responses. One example, among others, is in acute respiratory acidosis, where the increased $\mathrm{CO}_{2}$, by penetrating the CNS medullary center, stimulates the central ventilatory response, decreasing the net degree of hypoventilation until a new steady state of hypercapnia occurs.

Metabolic disturbances are not only compensated by pulmonary ventilatory responses but also by elaborate renal mechanisms. For example, in order to induce meta- bolic acidemia, lost quantities of bicarbonate-containing diarrhea must exceed the renal ability to adaptively produce and excrete urinary ammonia as ammonium chloride. The same is true of an acid load through dietary protein intake: high animal protein intake, with its acid metabolites, may not induce metabolic acidemia in a patient with healthy renal function, as it might in a person with decreased renal mass in chronic kidney disease.

\section{The Role of the Liver in Acid-Base Balance}

There is a relationship between acid-base balance and the hepatic urea cycle in which neutral urea is formed from bicarbonate and ammonia [10]. Ammonia formed by body cells is brought to the liver by red blood cells, which take up ammonia via membrane glycoproteins of the Rh family. Entry into the urea cycle is accomplished by the enzyme carbamoyl phosphate synthetase. Metabolic acidosis, acting like a stress response, is associated with an increase in catecholamines and corticosteroids, leading to protein catabolism and the production of increased amounts of ammonia to accompany the low bicarbonate concentrations. Acidosis decreases hepatic ureagenesis; ammonia is then shunted to form hepatic glutamine rather than urea, a process that spares bicarbonate $[3,11]$. The increased ammonia produced by the kidney is a result of increased glutamine uptake into proximal tubule cells and acidosis-stimulated renal glutaminase. In this way metabolic acidosis increases glutamine production in liver and increases ammonia produced in kidney. There is a small shift in urinary nitrogen excretion from urea to ammonia. Hepatic failure often is associated with acid-base disorders by many mechanisms [12]: decreased renal perfusion and urine output limit the renal acidification mechanisms causing metabolic acidosis, and respiratory alkalosis is common in part related to CNS-induced hyperventilation.

\section{Effects of Decreased Pulmonary and Renal Function on Acid-Base Balance}

In patients who have acute or chronic pulmonary disease, a common feature is respiratory acidosis or alkalosis. Patients with acute respiratory alkalosis may elevate their $\mathrm{pH}$ to greater than 7.7, unless they have underlying chronic lung disease. In terms of compensation for metabolic disturbances, patients with compromised lung function may have exaggerated hypoventilatory respons- 
Table 1. Expected compensation in acid-base disorders

\begin{tabular}{|c|c|}
\hline Primary disorder & Expected compensation \\
\hline Metabolic acidosis & $\begin{array}{l}\text { Steady within } 12-24 \mathrm{~h} \\
\left.\text { Expected } \mathrm{PaCO}_{2}=1.5 \text { [measured } \mathrm{HCO}_{3}\right]+8 \pm 2 \mathrm{~mm} \mathrm{Hg} \text { (Winter's) [15] }\end{array}$ \\
\hline Metabolic alkalosis & $\begin{array}{l}\text { Most variable } \\
\text { Expected } 0.5 \mathrm{~mm} \mathrm{Hg} \text { increase in } \mathrm{PaCO}_{2} \text { per } 1 \mathrm{mmol} / \mathrm{L} \text { increase in } \mathrm{HCO}_{3} \\
\text { Expected } \mathrm{PaCO}_{2}=0.7 \text { [measured } \mathrm{HCO}_{3}{ }^{-2} \text { ] }+40 \pm 2 \mathrm{~mm} \mathrm{Hg}[16,17]\end{array}$ \\
\hline Respiratory acidosis & $\begin{array}{l}\text { Acute: } \\
\text { Expected } 1 \mathrm{mmol} / \mathrm{L} \text { increase in } \mathrm{HCO}_{3} \text { per } 10 \mathrm{~mm} \mathrm{Hg} \text { rise in } \mathrm{PaCO}_{2}[18] \\
\text { Chronic }(24-36 \mathrm{~h}) \text { : } \\
\text { Expected } 3-5 \mathrm{mmol} / \mathrm{L} \text { increase in } \mathrm{HCO}_{3} \text { per } 10 \mathrm{~mm} \mathrm{Hg} \text { rise in } \mathrm{PaCO}_{2} \text { [19] }\end{array}$ \\
\hline Respiratory alkalosis & $\begin{array}{l}\text { Acute: } \\
\text { Expected } 1-2 \mathrm{mmol} / \mathrm{L} \text { fall in } \mathrm{HCO}_{3} \text { per } 10 \mathrm{~mm} \mathrm{Hg} \text { fall in } \mathrm{PaCO}_{2}[20] \\
\text { Chronic }(24-36 \mathrm{~h}) \text { : } \\
\text { Expected } 4-5 \mathrm{mmol} / \mathrm{L} \text { fall in } \mathrm{HCO}_{3} \text { per } 10 \mathrm{~mm} \mathrm{Hg} \text { fall in } \mathrm{PaCO}_{2}[21,22]\end{array}$ \\
\hline
\end{tabular}

es to alkalosis and inadequate hyperventilatory responses to acidosis [13]. Given that there exists a minimal $\mathrm{pCO}_{2}$ achievable by even the normal lung, compensations for metabolic acidosis are likely to be incomplete in pulmonary disease. That is why severe degrees of metabolic acidosis need to be treated, or ventilator supported, in order to avoid the consequence of abrupt drops in blood $\mathrm{pH}$ with any further acidemic insult or tiring of respiratory muscles.

The patient with kidney failure (less functional mass) is more vulnerable to develop acidemia because of a limitation in ammoniagenesis. Resisting acidifying responses to any imposed metabolic acidosis or respiratory acidosis is impaired in renal failure, since both of those disordersdependonrenalammoniagenesisforcompensation. Renal disease itself will be associated with normal acidbase balance unless the maximum amounts of ammonia necessary to excrete the normally produced acid load are exceeded. That is why patients with low glomerular function, compared to normal, will have a greater tendency to have acidosis with high-protein diets, smaller quantities of bicarbonate-containing diarrhea, or lesser degrees of organic anion acidosis. If the disease preferentially affects the renal tubules where acid secretion occurs, acidemia will be even more severe. Chronic tubulointerstitial diseases are frequently associated with renal acidosis and hyperkalemia. Patients with acute respiratory acidosis and kidney failure may not have the capacity for renal compensation characteristic of chronic respiratory acidosis if inadequate ammonia is available to enable acid elimination. Such patients will continue to be severely acidemic and will require adequate bicarbonate replacement to substitute for the expected renal contribution.

On the other hand, low levels of glomerular filtration will decrease the amount of bicarbonate filtered. In acidosis this will decrease amounts of bicarbonate lost in the urine; in proximal renal tubular acidosis, the decreased bicarbonate filtration will decrease the severity of, or even cure, the proximal acidosis. Yet, due to low bicarbonate filtration, an attempt to alkalinize the urine of a nonacidemic patient (e.g., in tumor lysis syndrome, myoglobinuria, or paraproteinemia) may cause the patient's blood to become alkalemic while the urine $\mathrm{pH}$ may remain acid, contrary to the original goal.

\section{Completeness of Compensations for Acid-Base Disorders}

Another observation is that systemic acid-base disturbances are unable to fully compensate [14]. In theory, full compensation could occur in systemic disease, but almost always, compensation is incomplete (Table 1) [15-22].

What could be the reason for this phenomenon? In metabolic acidosis, the sympathetic nervous system and corticosteroids are elevated (a reason for leukocytosis and hypercatabolic rate). The acid $\mathrm{pH}$ and low bicarbonate both stimulate the peripheral chemosensors signaling the medullary center to increase ventilation; the increased ventilatory response results in energy consumption by muscle, including respiratory muscles. On physical exam, patients with chronic metabolic acidosis are noted to have 


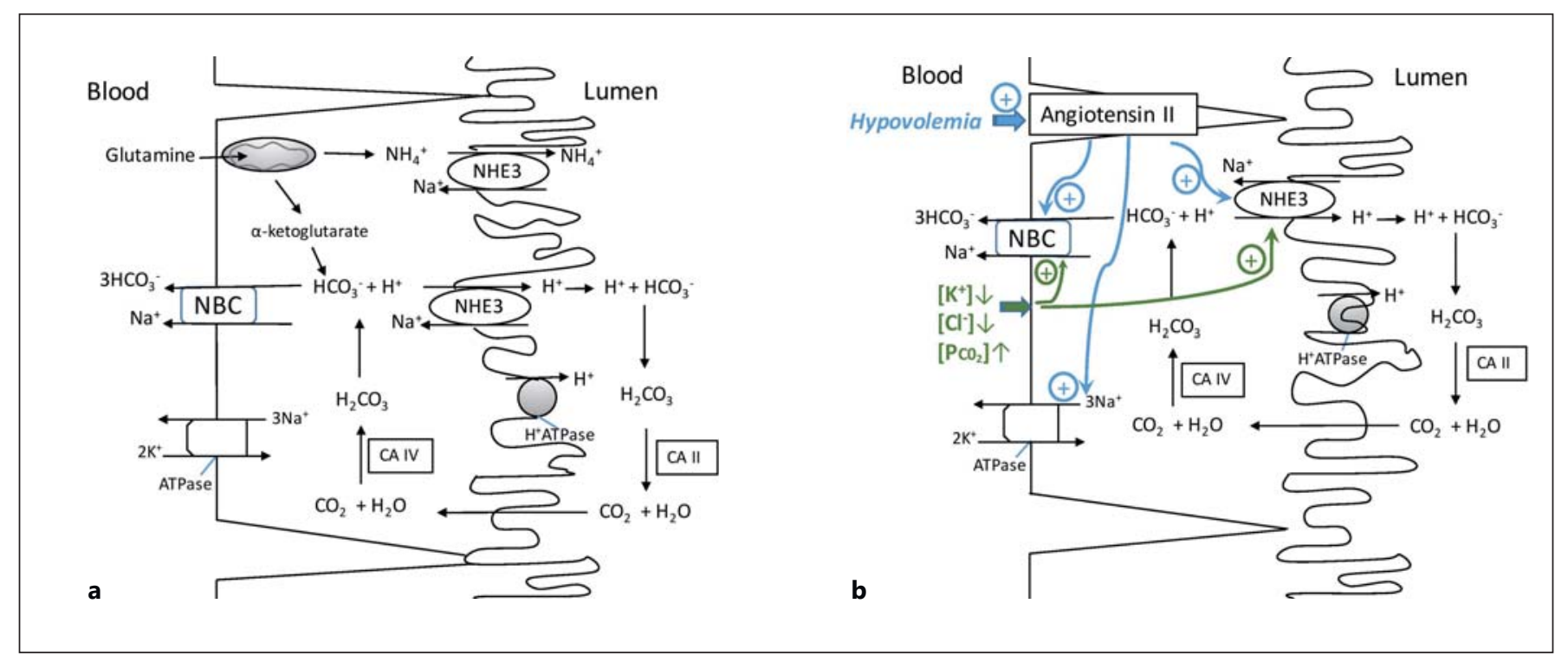

Fig. 1. a Proximal tubular cells. Compensation in both metabolic acidosis and respiratory acidosis depends on ammoniagenesis that occurs within proximal tubular cells and is limited especially when renal failure develops. Proximal (type 2) renal tubular acidosis is caused by decreased $\mathrm{HCO}_{3}{ }^{-}$reabsorption, which results from generalized proximal tubule dysfunction or specific cellular abnor- malities in $\mathrm{Na}^{+}-\mathrm{H}^{+}$exchanger (NHE3), $\mathrm{H}^{+}$ATPase, $\mathrm{Na}^{+} \mathrm{HCO}_{3}^{-}$ symporter (NBC), or carbonic anhydrase (CA). b Proximal tubular cells in metabolic alkalosis. Hypovolemia, hypokalemia, hypochloremia and increased $\mathrm{pCO}_{2}$ are all essential to maintaining metabolic alkalosis. inspiratory retraction of their intercostal muscles and breathe at high tidal volumes (Kussmaul). The work of breathing is increased [23]. A trade-off exists when compensation is incomplete: the $\mathrm{pH}$ rises enough to maintain survival but stops short of full compensation to spare major energy loss in order to maintain life for a longer period of time. An analogy is the classic blue bloater who hypoventilates and pink puffer who hyperventilates in chronic obstructive pulmonary disease: the hypercapnic patient exerts less muscle energy than the emphysematous patient who ventilates excessively to maintain oxygen tension.

What limits compensation for metabolic acidosis by the kidney is limited capacity for ammoniagenesis, so that despite the adaptive increase in tubular proton secretory mechanisms, new bicarbonate cannot be generated (Fig. 1a). The limitation for full compensation of metabolic alkalosis is related to the developed effect of coexisting hypokalemia, volume depletion and hyperaldosteronism which maintain metabolic alkalosis in order to maintain balance of salt, water, and potassium (Fig. 1b). Only early in vomiting, for example, does the increased filtered bicarbonate reach the urine. Thereafter, increased reabsorption of bicarbonate due to high angiotensin II from volume depletion and hypokalemia lead to maintenance of the alkalemia and the "paradoxical aciduria" of metabolic alkalosis [24]. This maintenance represents the limits of compensation: the shared effects of high plasma bicarbonate, low potassium, and extracellular volume depletion are more survivable than complete compensation of alkalosis with likely fatal potassium loss and/or hypovolemia. The respiratory compensation for metabolic alkalosis is limited by other stimuli for ventilation. The hypoventilatory response caused by elevated bicarbonate and $\mathrm{pH}$ at the level of the peripheral chemosensors is antagonized by hypoxemia which develops with hypoventilation. The set point of the chemosensors for $\mathrm{pO}_{2}$ is 60 $\mathrm{mm} \mathrm{Hg}$ (corresponding to oxygen saturations $>90 \%$ ) such that levels lower than that will trigger a response in the brain interstitial fluid to increase ventilation [25]. As a consequence, metabolic alkalosis results in the most variable and incomplete of the compensations.

Renal compensation for respiratory acidosis is enhanced by sodium bicarbonate reabsorption and new bicarbonate generation in the distal nephron and is limited by fluid and electrolyte balance and ammoniagenesis. The decreased glomerular filtration rate due to hypoxemia and hypercarbia and the increased bicarbonate reabsorption 
caused by high $\mathrm{pCO}_{2}$ causes extracellular volume expansion (as in cor pulmonale). The elevated plasma bicarbonate level (and low chloride) reaches a new steady state much like the steady state of mineralocorticoid excess: newly elevated plasma bicarbonate increases the filtered load of bicarbonate enough so that, even under the influence of hypercapnia to increase proximal tubular reabsorption of sodium bicarbonate, sufficient delivery of bicarbonate to the distal nephron allows for no further generation of new bicarbonate [26]. And since bicarbonate generation depends on ammonia present in the collecting duct lumen, the limited maximal capacity for ammonia synthesis is important. In this sense, the compensation is maintained by the high $\mathrm{pCO}_{2}$ and low chloride in analogy to primary hyperaldosteronism where the maintenance of high bicarbonate concentrations is determined by hypokalemia and will correct when potassium is repleted. The chloride depletion is essential to the elevated bicarbonate in compensated respiratory acidosis. In fact, if the $\mathrm{pCO}_{2}$ is abruptly lowered by mechanical ventilation, a posthypercapnic metabolic alkalosis will develop and persist until adequate chloride is replenished [27].

Respiratory alkalosis in the chronic phase is somewhat different from all the others. As long as glomerular filtration is not reduced to a great extent, the hypocapnic-driven decreased reabsorption of sodium bicarbonate by the proximal tubule results in bicarbonaturia. This disorder may at times compensate completely to normal $\mathrm{pH}$. A limitation of bicarbonaturia and therefore full compensation would be low filtration and increased proximal reabsorption from extracellular depletion that could occur as a result of the urinary loss of sodium. Otherwise the more passive excretion of filtered bicarbonate will stop only when filtered bicarbonate decreases. This is analogous to the way bicarbonaturia stops in the setting of proximal tubular acidosis.

\section{The Diagnostic Approach to Identifying Acid-Base Disorders}

The usual diagnostic approach to an acid-base disorder begins with a complete history and physical examination. Clues in the history include: understanding the quantity, contents, and source of fluid losses or gains from the body; ingested substances and certain diseases known to be associated with acid-base disorders. Examples include vomiting (metabolic alkalosis), diarrhea (metabolic acidosis), chronic obstructive pulmonary disease (respiratory acidosis), pneumonia (respiratory alka-

Perspectives in Acid-Base Balance losis), and so on. Laboratory tests are usually performed including a basic metabolic profile with electrolytes: sodium, potassium, chloride, bicarbonate, blood urea nitrogen, and creatinine. The bicarbonate concentration alone does not prove a metabolic disturbance because there are two other variables in equilibrium with bicarbonate: carbon dioxide and the hydrogen ion concentration. A low plasma bicarbonate is consistent with either metabolic acidosis or respiratory alkalosis. Respiratory alkalosis can be mistaken for renal tubular acidosis if only the plasma bicarbonate is measured. The level will be low, and the urine $\mathrm{pH}$ elevated, in both renal acidosis and respiratory alkalosis; a blood gas analysis of $\mathrm{pH}$ will distinguish the two disturbances.

When blood gases are drawn and both the $\mathrm{pH}$ and bicarbonate are low, there is at least a component of metabolic acidosis and that disorder is the dominant process. However, the finding of a metabolic acidosis does not rule out multiple processes simultaneously present. There are many findings that can be used to diagnose mixed disturbances. Once the dominant process is identified, it is necessary to assess the degree of compensation by looking at empirical data. For example, normal respiratory compensation for metabolic acidosis is predicted based on the expected relationship between bicarbonate and $\mathrm{pCO}_{2}$ established by empirical observation of subjects with simple metabolic acidosis [1]. Should the actual $\mathrm{pCO}_{2}$ be lower than the predicted value, the diagnosis of respiratory alkalosis as second primary disturbance can be made. If the actual $\mathrm{pCO}_{2}$ is higher than predicted, then a simultaneous respiratory acidosis is present. It is apparent that both metabolic acidosis and its hyperventilatory compensation cause $\mathrm{pCO}_{2}$ and bicarbonate to fall. The patient with chronic metabolic acidosis who then develops primary hyperventilation may further decrease the bicarbonate concentration while increasing $\mathrm{pH}$.

After the compensatory response to a metabolic acidosis is determined, it is possible to exclude the presence or absence of a primary respiratory disorder, but a mixed metabolic disturbance is still possible. For example, Winter's equation is valid in a mixed metabolic disturbance of metabolic acidosis and alkalosis when the predominant process is acidosis [15]. In the case where a high chloride acidosis and a low chloride alkalosis coexist, it is not possible to differentiate this double disturbance from a simple metabolic acidosis. However, it is then useful to determine the serum anion gap. The anion gap is determined by subtracting the sum of chloride and bicarbonate from the serum sodium concentration [28]. The normal value is approximately $10-12 \mathrm{mEq}$ per liter corresponding to an 
Table 2. Causes of anion gap metabolic acidosis (mnemonic: GOLD MARK)

\begin{tabular}{ll}
\hline G & Glycols (ethylene and propylene) \\
O & Oxoproline \\
L & L-Lactate \\
D & D-Lactate \\
M & Methanol \\
A & Aspirin (salicylates) \\
R & Renal failure (uremia), rhabdomyolysis \\
K & Ketoacidosis (alcoholic, diabetic) \\
\hline
\end{tabular}

Table 3. Causes of hyperchloremic acidosis

\begin{tabular}{ll}
\hline Renal & Defect in $\mathrm{H}^{+}$secretion: distal RTA, type 1 \\
& Defect in $\mathrm{HCO}_{3}{ }^{-}$reabsorption: proximal RTA, type 2 \\
& Aldosterone deficiency or resistance: hyperkalemic \\
& RTA, type 4 \\
& Urinary loss of organic anion: ketoacidosis, toluene \\
& intoxication
\end{tabular}

amount of charge associated with a normal albumin concentration at normal $\mathrm{pH}$. An elevated anion gap is definitive for a metabolic acidosis (Table 2) [29].

Not only is the presence of an anion gap helpful in the differential diagnosis of the metabolic acidosis, it is also useful in determining the presence of a mixed metabolic disturbance. The calculation of the increment in anion gap is determined as the observed anion gap minus a normal anion gap of $10 \mathrm{mEq}$ per liter. A similar calculation of the decrease in bicarbonate concentration can be made by subtracting the observed bicarbonate concentration from a normal bicarbonate of $25 \mathrm{mEq}$ per liter. The comparison can then be made between the "delta anion gap" and the "delta bicarbonate." If this relationship is approximately 1 : 1 , then it is likely that the disorder is simply an anion gap acidemia. However, if the change in anion gap is greater than the drop in bicarbonate from normal, then there is a process raising the bicarbonate concentration. Such a process is a metabolic alkalosis which may be associated with hypochloremia. An example of this kind of mixed disorder would be a patient who is vomiting and has lactic acidosis or ketoacidosis. If you consider that the maximum drop of bicarbonate is $<25 \mathrm{mEq}$ per liter, then any rise of an anion gap $>25$ would necessitate a change in concentration of another ion, since bicarbonate cannot reach negative values, and electroneutrality must hold. In this situation, hypochloremia is frequently observed, suggesting movement of chloride into cells. The result is hypochloremic, anion gap metabolic acidosis. If the bicarbonate concentration fell more than the anion gap rose, then the second process is most likely a hyperchloremic acidosis (Table 3).

In the setting of a metabolic acidemia, if the urine contains sodium and potassium with any anion other than chloride, the result will be hyperchloremia [30]. If the urinary anion is bicarbonate, then the hyperchloremic acidosis that results is known as a renal tubular acidosis. If the excreted anion is not bicarbonate, for example ketoacid or lactate anion, then the appearance in the blood will also be that of a hyperchloremic acidosis. In the extreme, where all the organic anion is excreted with sodium and potassium in the urine, the appearance in the blood will be that of a nonanion gap hyperchloremic metabolic acidosis. Some patients with ketoacidosis or glue-sniffing acidosis due to hippurate derived from toluene, who have a high glomerular filtration rate, can present with a hyperchloremic acidosis; rather than having a blood anion gap, the urine demonstrates the charge gap. In that way, a gap acidosis may be misdiagnosed as a renal tubular acidosis.

\section{Two Approaches to Understanding Acid-Base Balance}

Since only a single blood $\mathrm{pH}$ exists at a given time (the isohydric principle), the $\left[\mathrm{H}^{+}\right]$must be in equilibrium with many buffer substances that can take up or release hydrogen according to individual rate constants, which are related to a dissociation constant known as the $\mathrm{pK}$. As blood $\mathrm{pH}$ changes, the contribution of each buffer-pair to take up hydrogen changes, making the bookkeeping for the $\left[\mathrm{H}^{+}\right]$very complex. In other words, what is the fate of those hydrogen ions as $\mathrm{pH}$ changes from normal? Thus, it is problematic to choose a single buffer system to explain acid-base phenomena. Yet, the isohydric principle is the basis of the traditional approach using bicarbonate and $\mathrm{pCO}_{2}$ to understand acid-base balance [31].

$$
\mathrm{CO}_{2}+\mathrm{H}_{2} \mathrm{O} \leftrightarrow \mathrm{H}_{2} \mathrm{CO}_{3} \leftrightarrow \mathrm{HCO}_{3}{ }^{-}+\mathrm{H}^{+}
$$

or

$$
\mathrm{pH}=\mathrm{pK}+\log \left[\mathrm{HCO}_{3}^{-}\right] / 0.03\left(\mathrm{pCO}_{2}\right)
$$

In the above equation, 0.03 is the solubility factor for carbon dioxide in solution, and the $\mathrm{p} K$ is the overall disso- 
ciation constant for carbon dioxide and bicarbonate. The isohydric principle states that the hydrogen ion concentration is equal to the ratio of acid to base multiplied by the dissociation constant for each buffer pair in the body that can pick up a proton. This includes phosphate, albumin, hemoglobin and a host of other proteins. This becomes a nonlinear relationship for bicarbonate since the ratio for each buffer pair is different for differing $\mathrm{pH}$, a fact central to the definition of $\mathrm{pK}$. This is a weakness of relying completely on the bicarbonate $/ \mathrm{pCO}_{2}$ approach for understanding acid-base disturbances. This weakness is illustrated by the equation below, used clinically to determine replacement amounts of bicarbonate for an acidemic patient to normalize the bicarbonate concentration:

$\mathrm{HCO}_{3}{ }^{-}$deficit $(\mathrm{mEq})=\left(\right.$ desired $\left[\mathrm{HCO}_{3}{ }^{-}\right]-$measured $\left.\left[\mathrm{HCO}_{3}{ }^{-}\right]\right)$ $\times 0.5 \times$ body weight $(\mathrm{kg})$

In this equation, it would appear that the bicarbonate volume of distribution is 0.5 - (body weight) or total body water [32]. However, a more likely estimate of bicarbonate's volume of distribution is closer to the extracellular volume, or 0.2 - (body weight). The percent of total body buffering capacity contributed by the bicarbonate $/ \mathrm{CO}_{2}$ system at normal $\mathrm{pH} 7.40$, is 0.4 . In the above equation, the 0.5 represents the ratio of the extracellular volume of distribution of bicarbonate divided by the contribution of bicarbonate as a buffer, or $[0.2 \cdot$ (body weight) $] / 0.4$, or 0.5 - (body weight). This equation is used to estimate the bicarbonate deficit or excess and therefore is used as a guide to replacement of bicarbonate in acidosis or $\mathrm{HCl}$ in alkalosis. However, the percent contribution of bicarbonate is not always the 0.4 value it is at pH 7.4. It falls as bicarbonate goes down in acidosis and rises as bicarbonate goes up in alkalosis. The nonlinear change is due to the different buffer capacity of bicarbonate/ $\mathrm{CO}_{2}$ at different $\mathrm{pH}$; it is of much more importance at high $\mathrm{pH}$ than low $\mathrm{pH}$. Furthermore, one would not likely consider bicarbonate replacement in a patient with a $\mathrm{pH}$ of 7.40 . What this means is that due to the nonlinearity of the isohydric principle, the apparent volume of distribution for bicarbonate increases with acidosis and decreases with alkalosis due to the relative importance of bicarbonate versus phosphates and other proteins as $\mathrm{pH}$ changes. Clinically, the apparent volume of distribution could exceed body weight if calculated in acidosis since more bicarbonate than expected would need to be given to correct severe acidosis. Despite these shortcomings, the calculation can be successfully used if only a fraction of the calculated amount is given and re-calculations are frequent. Of

Perspectives in Acid-Base Balance greatest danger is using this equation to calculate an amount of $\mathrm{HCl}$ to give an alkalemic patient to lower the serum bicarbonate. Since the apparent volume of distribution is much less than would be calculated from this equation, the chances of overtreating with acid are great.

Another consequence of the isohydric principle is that in vomiting-induced losses of hydrochloric acid, the amount of hydrogen ion that is lost is equal to the chloride that is lost, not to the amount of bicarbonate that is gained in the extracellular fluid. In other words, because there is a high blood $\mathrm{pH}$, the bicarbonate distribution will be smaller than predicted by the 0.5 - (body weight) noted in the equation above. Since the buffer capacity of bicarbonate is greater than predicted for $\mathrm{pH}$ of 7.4, the bicarbonate rise in blood will be greater than the actual loss of hydrogen ion.

The traditional approach often considers acid-base and electrolyte disorders separately, whereas in clinical practice the disturbances are interconnected. Take acute versus chronic respiratory acidosis as example: when the $\mathrm{pCO}_{2}$ abruptly increases, there is a limited ability to compensate for the drop in $\mathrm{pH}$ induced by the high $\mathrm{pCO}_{2}$. That is because there is no room electrically speaking, in the extracellular fluid for additional bicarbonate anion needed to compensate. That would require a decrease in another anion or a rise in cation for electroneutrality purposes. Only after the renal excretion of the anion chloride in the urine does the serum bicarbonate concentration rise. This could be viewed as a time-dependent increase in ammoniagenesis and ammonium chloride excretion which then allows for bicarbonate concentration to be maintained at a higher level. In other words, it is the hypochloremia that allows maintenance of electroneutrality, and increases in plasma bicarbonate concentration as acute respiratory acidosis transitions to chronic respiratory acidosis. Two interpretations of this phenomena are either that the compensation is primarily due to an increase in renal bicarbonate generation versus the excretion of chloride to maintain electroneutrality [33-38]. In both cases, the importance of ammonium in the urine is significant.

\section{Electroneutrality and Acid-Base Balance}

Most acid-base disorders develop in the context of either gains of fluid and electrolytes or losses of fluid and electrolytes from the body. To begin our discussion, let us only consider strong ions that are completely dissociated in body fluids. For the moment, we will not consider the 
hydrogen and bicarbonate ion concentrations. If the normal extracellular sodium concentration is $140 \mathrm{mM}$ and chloride concentration is $100 \mathrm{mM}$, then a gain or loss of fluid with precisely those same concentrations should have no effect on acid-base balance. If the gain or loss contains concentrations of sodium and chloride that differ from that relationship of 140/100, then after osmoregulatory normalization of the plasma sodium concentration, the resultant chloride concentration will differ from normal. For example, if the loss from the extracellular fluid compartment contained relatively more chloride than sodium, then the change observed for electrolytes in the extracellular fluid would be hypochloremia. If the loss contained relatively less chloride than sodium compared to the normal extracellular fluid content, then the result would be hyperchloremia. The same consequences on the extracellular fluid sodium and chloride concentrations would occur if the gains of fluid containing sodium and chloride were disproportionate to normal extracellular fluid values. For example, if isotonic sodium chloride were infused into a patient, there would be a tendency for hyperchloremia to develop because the 1:1 relationship of sodium to chloride in saline contains relatively more chloride than sodium. Similarly, if sodium and chloride were lost from the body in a 1:1 relationship, the effect after osmoregulation would be hypochloremia.

To begin the discussion of acid-base disorder generation, we would need to know the contents of electrolytes in any gained or lost fluid. Abnormalities in acid-base balance could derive from the ingestion or the loss of sodium or chloride salts. For the most part, losses occur through the gastrointestinal tract, sweat or urine. Within the gastrointestinal tract, there are secretions that may be lost that are quite different depending on the site of loss. For example, the stomach usually contains proportionately more chloride than sodium even in the case where $\mathrm{HCl}$ secretion into the stomach is blocked by an antacid such as a proton pump inhibitor. The small intestine containing pancreatic secretions usually contains much larger concentrations of sodium than of chloride. Colonic secretions that result in diarrheal losses usually contain more sodium than chloride but not always. In some cases such as with villous adenoma, chloride is secreted, and therefore stool may be relatively rich in chloride compared to sodium. In the kidney, urinary losses may also vary in their relative content of sodium and chloride. For example, certain diuretics or genetic channelopathies result in relatively high chloride excretion compared to sodium. Other diuretics and channelopathies exhibit the opposite loss of cations disproportionate to chloride.
In this discussion, we have ignored potassium. In our calculations of gained or lost fluids affecting acid-base we will count potassium as similarly important to sodium. Excesses of extracellular potassium will enter cells in exchange for sodium, until the extra potassium substitutes for sodium in the urine. Similarly losses of potassium in stool or urine will result in cellular uptake of sodium by cells. This is the reason that sodium and potassium in stool, urine or intravenous fluids must be treated as losses or gains affecting the sodium concentration.

We now have a basis to predict whether hyperchloremia or hypochloremia would develop in any gain or loss of fluid containing electrolytes. This argument can predict the following:

Hyperchloremia will develop with the losses of nonchloride sodium salts from the small intestine, large intestine, and in some cases urine.

Hyperchloremia will develop with the gains of chloride salts such as sodium chloride, potassium chloride, calcium chloride, ammonium chloride, lysine hydrochloride, arginine hydrochloride, and so on.

Hypochloremia will develop with the losses of chloride salts within gastric secretions, and some forms of intestinal secretions that are rich in chloride.

Hypochloremia will develop with the gains of sodium salts low in chloride such as sodium citrate used with blood products, plasmapheresis or dialysis, sodium lactate or acetate. In these situations, the mechanism is not chloride that is lost but volume expansion with sodiumcontaining salts without chloride where the sodium concentration is normalized by osmoregulatory mechanisms.

Having established that the plasma chloride can increase or decrease, we next ask what does that have to do with acid-base balance and in particular what will be the response in plasma bicarbonate concentration? To answer this question we must use a construct that emphasizes the necessity to maintain electroneutrality $[39,40]$. The forces requiring electroneutrality in solution are very powerful, many million-fold greater than gravitational forces. So, we can assume that all cations must equal all anions to balance charge. Simply stated, if the chloride concentration goes up and the sodium concentration stays the same, an anion other than chloride must decrease. And if the chloride concentration goes down and the sodium concentration stays the same then an anion other than chloride must rise. According to this construct, the plasma anion that can change in concentration to maintain electroneutrality is bicarbonate anion. The reason $\mathrm{HCO}_{3}{ }^{-}$can do this is that the bicarbonate ion is in equilibrium with neutral species namely car- 
bon dioxide and water. In addition, the enzyme carbonic anhydrase which facilitates this reaction is ubiquitous in the body and of all enzymes has the highest turnover number.

To summarize, we recognize a metabolic acidosis by observing hyperchloremia, and metabolic alkalosis by hypochloremia. However, since ions other than chloride could be abnormal, we should consider increases or decreases in bicarbonate as a means to maintain electroneutrality in situations where nonchloride ions are abnormal. For example, the loss of negative charge due to hypoalbuminemia will result in an increase in the anion bicarbonate, a condition known as hypoproteinemic alkalosis [41]. The usual contribution of negative charge due to albumin is $2.5 \mathrm{mEq}$ per liter for every $1 \mathrm{~g} / \mathrm{dL}$ of albumin [42]. Another form of metabolic alkalosis without low chloride occurs with the relative increase in sodium concentration associated with increased sodium reabsorption by the principal cells of the renal collecting duct (Fig. 4). These syndromes, the prototype being hyperaldosteronism, are usually associated with hypokalemia and hypertension [43]. On the other hand, an increase in chloride reabsorption as occurs with activating mutations of the thiazidesensitive sodium chloride cotransporter will result in hyperchloremic acidosis with hypertension and hyperkalemia [44].

It is very important consequently to look at serum electrolytes carefully to evaluate the relationship between sodium and chloride. It is also important to correct the anion gap for any degree of hypoalbuminemia [45]. The anion gap which is usually defined as the difference between the plasma sodium and the sum of chloride plus $\mathrm{HCO}_{3}{ }^{-}$may be elevated in disease. In this case, a nonchloride and unmeasured anion is elevated, and for electroneutrality purposes the bicarbonate concentration will decrease. This group of disorders constitutes the anion gap acidosis $[1,46]$.

If one wishes to know what the kidney is doing with respect to electrolyte excretion, it is necessary to evaluate the urine chemistry. Considering sodium, potassium and chloride in the urine, the excretion of sodium and potassium concentrations relative to chloride that are disproportionate to that which exists in the extracellular fluid can predict whether the loss of that urine will have an acidifying or alkalinizing effect on the extracellular fluid. For example, if the sodium and potassium concentration greatly exceed the chloride concentration in urine, there will be a tendency to acidify the body fluids. If a metabolic acidosis exists in the blood, then such an excretion pattern by the kidney suggests that the kidney is the cul-
Table 4. Bicarbonate-centered and physicochemical approach

\begin{tabular}{ll}
\hline $\begin{array}{l}\text { Traditional approach } \\
\text { (bicarbonate centered) }\end{array}$ & $\begin{array}{l}\text { Physicochemical (Stewart) } \\
\text { approach }\end{array}$ \\
\hline $\mathrm{CO}_{2} / \mathrm{HCO}_{3}{ }^{-}$equilibrium & $\mathrm{CO}_{2} / \mathrm{HCO}_{3}{ }^{-}$equilibrium \\
$\mathrm{Henderson-Hasselbalch} \mathrm{equation}$ & $\begin{array}{l}\text { Electroneutrality } \\
\text { Anion gap }\end{array}$ \\
"Delta/delta" & $\begin{array}{l}\text { Water dissociation } \\
\end{array}$ \\
& Weak acid dissociation \\
\hline
\end{tabular}

prit in the generation of the acidosis. The diagnosis would then be called renal tubular acidosis and the unmeasured anion accompanying sodium and potassium would likely be bicarbonate. On the other hand, if chloride was excreted in concentrations disproportionately high to the sum of sodium and potassium, then an alkalinizing effect on plasma would be predicted. If a systemic metabolic acidosis was present, then this pattern would be considered appropriate. We would then look for an extrarenal cause of metabolic acidosis such as diarrhea and consider the urinary pattern that of proper renal compensation. The extra chloride in the urine would need to be accompanied by an unmeasured cation which we know to be ammonium [47, 48].

Renal compensations for respiratory disturbances can also be inferred from urinary chemistry. For example, the renal compensation for respiratory acidosis should be the loss of urinary electrolytes in the pattern that would alkalinize the extracellular space. As discussed before, such a pattern of electrolytes would be the loss of high chloride concentrations relative to sodium and potassium. As previously discussed, the cation accompanying chloride is ammonium.

This way of analyzing acid-base disorders emphasizing electroneutrality or the bicarbonate/carbon dioxide model are not mutually exclusive (Table 4). It is important to realize that both are constructs used to help understand and manage acid-base disturbances, and experimental data can be interpreted using either method.

\section{Disorders Demonstrating the Relationship between Strong Electrolytes and Acid-Base Balance}

\section{Hypochloremic Alkalosis (Table 5)}

The traditional view to explain the metabolic alkalosis that accompanies vomiting or gastric drainage, is that the loss of $\mathrm{HCl}$ from the stomach results in bicarbonate extrusion from the parietal cell into the extracellular space 
Table 5. Causes of hypochloremic alkalosis

\begin{tabular}{ll}
\hline Renal & $\begin{array}{l}\text { Loop and distal tubule diuretics } \\
\text { Bartter's syndrome (Fig. 2) } \\
\text { Gitelman's syndrome (Fig. 3) } \\
\text { Hyperaldosteronism with hypokalemia } \\
\text { Posthypercapnic alkalosis }\end{array}$ \\
\hline Nonrenal & $\begin{array}{l}\text { Gastrointestinal: vomiting, nasogastric suction, } \\
\text { infectious gastroenteritis, congenital chloridorrhea, } \\
\text { villous adenomas } \\
\text { Chloride-rich sweat in cystic fibrosis }\end{array}$ \\
\hline
\end{tabular}

in exchange for chloride entry into the cell. Acidification of gastric fluids is accomplished by luminal $\mathrm{H}^{+}-\mathrm{K}^{+}$ATPase and parallel chloride secretion. On the basolateral membrane, there exists a $\mathrm{Cl}^{-}-\mathrm{HCO}_{3}{ }^{-}$exchanger, and the intracellular process by which an alkaline cell that has just lost its proton to the gastric lumen will produce bicarbonate from hydroxyl anion, and carbon dioxide is facilitated by carbonic anhydrase. The transfer of bicarbonate into the extracellular fluid occurs normally after eating, and accounts for the alkaline tide, an increased urinary $\mathrm{pH}$ observed after meals. However, with vomiting the losses are more severe and irrecoverable, so a metabolic alkalosis is generated. But is the elevation of bicarbonate in the blood equivalent to the amount of hydrogen ion lost in the gastric fluid? Because of the elevation in blood $\mathrm{pH}$ and according to the isohydric principle, the increase in bicarbonate appearing in the extracellular fluid should not be equivalent to milliequivalents of chloride disappearing from the extracellular fluid. The bicarbonate is involved in a relationship with hydrogen ions and the hydrogen ions are in turn in equilibrium with many systemic buffers so that depending on the $\mathrm{pH}$ developed, bicarbonate remaining as that anion in the extracellular bicarbonate will differ from the amount of hydrogen lost in the emesis. However, chloride has no such additional $\mathrm{pH}$-dependent distribution. Thus, the loss of chloride in emesis should balance the amount of chloride lost from the extracellular space. It follows that the better determinant of the plasma bicarbonate is the electroneutrality consequences of having lost more chloride than sodium. Furthermore, the amount of total chloride in the extracellular space is approximately $1,000 \mathrm{mEq}$, far less than the quantity of hydrogen associated with the mass of weak acids and buffers within the body water. It would be much easier to do bookkeeping for chloride than for hydrogen ion or bicarbonate.
Returning to the effects of the generated alkalosis on body fluid chemistry, it should be noted that at first the individual with vomiting has not developed volume depletion, and aside from an elevated bicarbonate and a decreased chloride in the blood, few changes in renal function have occurred. The consequence appears to be corrective of the alkalosis with increased filtration of bicarbonate into the proximal tubule without enhanced reabsorption such that bicarbonaturia accompanied by natriuresis occurs. Urinary sodium is elevated, and output is high such that the patient notices polyuria.

With continued vomiting, enough urinary sodium and gastric chloride are lost to deplete the extracellular volume. Subsequently, the renin-angiotensin aldosterone system is increased. Angiotensin II (Fig. 1b) stimulates proximal tubule sodium-hydrogen exchange and sodium bicarbonate reabsorption preserving sodium and water appropriately for the depleted circulatory condition. However, a consequence of this conservation is also retention of bicarbonate which begins to prevent correction of alkalosis. Another effect of bicarbonate reaching the distal nephron with sodium when aldosterone is increased is the loss of potassium to replace sodium in the urine. At this time, the urine $\mathrm{pH}$ is high but starting to fall and the urinary sodium to potassium ratio starts to favor potassium. The results are hypokalemia and potassium depletion since it is unlikely that the patient is able to hold down adequate meals. Hypokalemia (Fig. 1b) in turn also increases proximal tubule sodium hydrogen exchange and sodium bicarbonate cotransport thereby increasing further the proximal retention of sodium and bicarbonate. In the distal nephron, sodium reabsorption via the epithelial sodium channel of the collecting duct principal cell is increased by aldosterone. At this stage of metabolic alkalosis, volume depletion is present despite sodium present in the urine [49].

Aldosterone also increases intercalated cell proton secretion resulting in further bicarbonate reabsorption. Eventually, due to hypokalemia, the $\mathrm{K}^{+}-\mathrm{H}^{+}$exchanger in the intercalated cell reabsorbs potassium and secretes hydrogen, which further leads to net bicarbonate reabsorption ( Fig. 5a). At this late stage of vomiting, the volume depletion and hypokalemia have led to complete bicarbonate reabsorption, a process known as maintenance of metabolic alkalosis. The urinary $\mathrm{pH}$ becomes acid as the urine becomes bicarbonate free. This is known as paradoxical aciduria. The urine will be concentrated and will contain little sodium, bicarbonate and even potassium since the latter will undergo increased reabsorption due to the $\mathrm{H}^{+}-\mathrm{K}^{+}$ATPase. The absence of bicarbonate from 


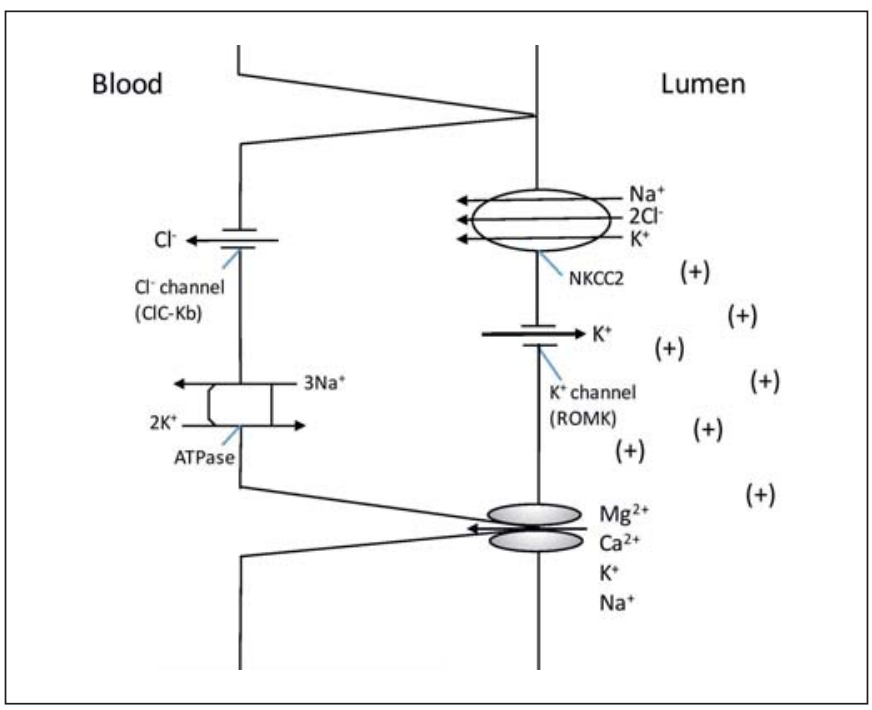

Fig. 2. Thick ascending limb cell of the loop of Henle. Mutations in bumetanide-sensitive $\mathrm{Na}-\mathrm{K}-\mathrm{Cl}$ cotransporter (NKCC2), epithelial $\mathrm{K}^{+}$channel (renal outer medullary potassium channel, ROMK), kidney-specific chloride channel ( $\mathrm{ClC}-\mathrm{Kb})$, or use of furosemide causing inhibition on NKCC2 may cause Bartter's syndrome, with hypokalemic hypochloremic metabolic alkalosis as well as extracellular fluid depletion. Not shown is the calcium receptor at the basolateral side of this cell type. During hypercalcemia, the calcium receptor is stimulated and leads to an inhibition of NKCC2, resulting in furosemide-like diuresis and a decreased voltage in the lumen causing hypercalciuria.

urine spares potassium loss since bicarbonate has a kaliuretic effect. Urinary chloride will be low throughout this process consistent with the hypochloremia. Chloride retention occurs early and continues by mechanisms of proximal and distal chloride reabsorption particularly driven by low extracellular chloride. The process will continue until chloride salts of sodium and potassium are repleted either by the patient or by medical intervention. Potassium chloride is necessary because otherwise volume expansion will increase the losses of retained bicarbonate, a process that will severely deplete potassium further. From the vantage point of membrane transporters participating in the response to metabolic alkalosis, it must be appreciated that there is significant overlap in function of the antiporters for sodium and hydrogen, chloride and bicarbonate, potassium and hydrogen, implying complex interconnections between acid-base balance and the economy of fluid and electrolytes. The same is true for various hormones, like angiotensin II and aldosterone that connect acid-base and electrolyte regulation.

Perspectives in Acid-Base Balance

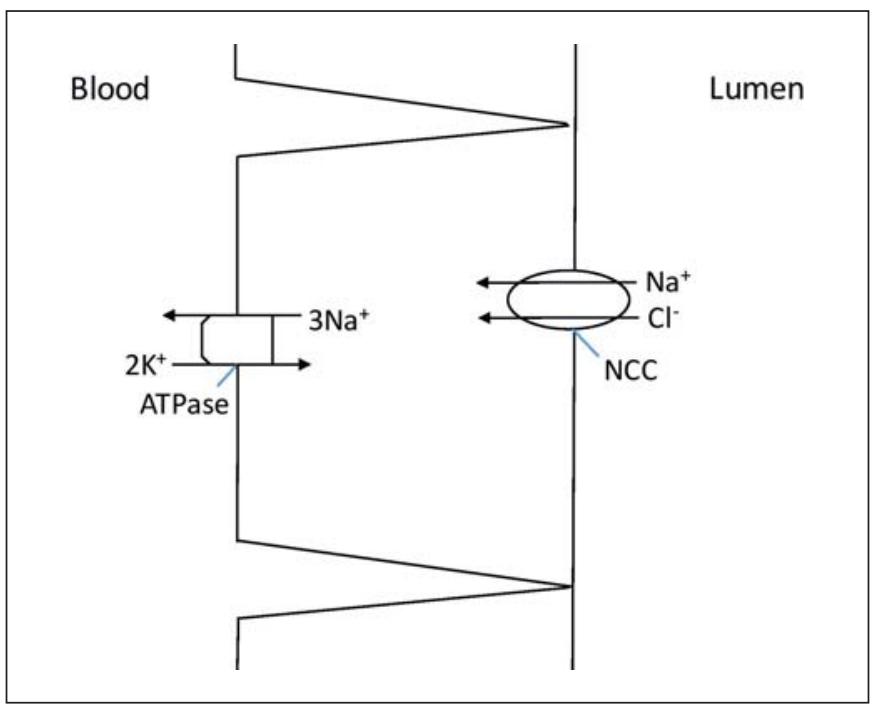

Fig. 3. Cortical distal tubular cell. Activation of $\mathrm{NaCl}$ cotransporter (NCC) in pseudohypoaldosteronism type II (Gordon syndrome) causes hyperchloremic hyperkalemic acidosis. Inhibition of NCC by thiazide, or an inactivating mutation in Gitelman's syndrome are causes of hypochloremic hypokalemic alkalosis. A decrease in NCC is in mechanism for the "aldosterone escape" in primary hyperaldosteronism.

Another view of this process focuses on the loss of chloride from the vomitus and the development of hypochloremia. For electroneutrality to be conserved, loss of extracellular chloride is replaced by an increase in the anion bicarbonate which is available from ambient water and carbon dioxide. The advantage of thinking of preservation of electroneutrality in this way is that this form of alkalosis can be recognized by a low serum chloride, and thus chloride losses from the body are assumed. A knowledge of the fluid contents of various body fluids can help establish a differential diagnosis. For example, hypochloremic alkalosis may be the result of chloride loss associated with chloriuretic diuretics (loop and thiazide diuretics), and other renal causes such as the channelopathies Bartter's and Gitelman's syndromes (Fig. 2, 3, 5b). In addition to vomiting, another nonrenal cause of this form of alkalosis includes sweating in cystic fibrosis. A finding of a low urinary chloride concentration in nonrenal metabolic alkalosis will distinguish these from the renal causes which are associated with high urinary chloride [50].

An advantage of associating an acid-base abnormality with the content of fluids lost rather than a specific site of loss is helpful diagnostically. For example, not all vomit- 


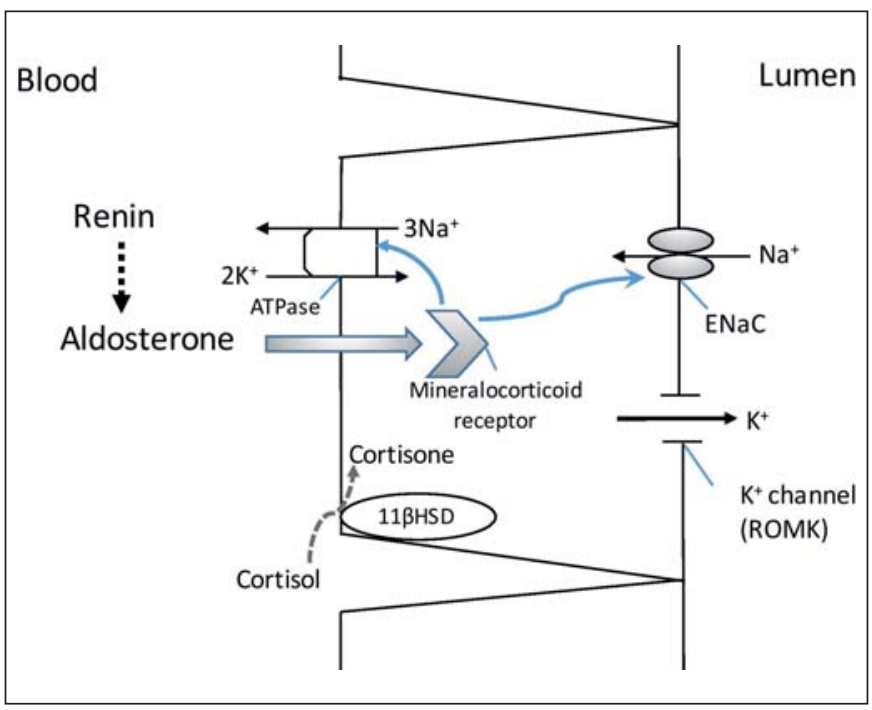

Fig. 4. Principal cell in cortical collecting duct. Increased epithelial sodium channel $(\mathrm{ENaC})$ as in Liddle syndrome, and hyperaldosteronism, either primary or secondary, may cause hypokalemic alkalosis with hypertension. Decreased ENaC, mineralocorticoid receptor blockade, and type 4 renal tubular acidosis resulting from hypoaldosteronism or aldosterone resistance present with hyperkalemic acidosis with hypotension.

ing contains $\mathrm{HCl}$; upper small bowel losses may cause metabolic acidosis. Similarly, not all diarrhea contains bicarbonate, sometimes the accompanying anion is acetate or butyrate from bacterial metabolism. Not all diarrhea losses are low in chloride. High chloride losses may cause alkalosis not acidosis. From a transport perspective, chloride absorption in the ileum may be decreased by a loss of function mutation of ileal $\mathrm{Cl}^{-}-\mathrm{HCO}_{3}{ }^{-}$exchange causing metabolic alkalosis.

\section{Nonhypochloremic Metabolic Alkalosis}

Another type of metabolic alkalosis is associated with hypertension not hypotension and includes causes such as mineralocorticoid excess syndromes. These are usually recognized by some degree of volume expansion, hypertension, a low potassium and usually moderate metabolic alkalosis. If one examines the laboratory tests carefully, one will find that the sodium concentration is above normal in most cases at a level that is increased compared to chloride. This separation of sodium and chloride concentrations and the hypokalemia are related to sodium retention in the principal cell of the renal collecting duct (Fig. 4). This can be explained by a primary effect of mineralocorticoid to increase sodium but not chloride reabsorption. In order to maintain electroneutrality, the difference between sodium and chloride is made up for by an elevation in plasma bicarbonate. The volume expansion caused by hyperaldosteronism leads to a secondary downregulation of the thiazide-sensitive sodium chloride transporter such that some chloride losses occur, a process known as aldosterone escape [51]. Hypokalemia will maintain the metabolic alkalosis through its effects in the proximal tubule and will also lead to chloriuresis by decreasing chloride reabsorption. Treatment of this disorder involves blockade of the mineralocorticoid effect or surgical removal of an adrenal adenoma $[52,53]$.

The more traditional explanation for the metabolic alkalosis is that increased aldosterone leads to increased sodium reabsorption and potassium secretion with additional small amounts of bicarbonate added to the circulation by lumen negativity or aldosterone-dependent electrogenic proton secretion by ATPases of the alpha (type A) intercalated cell (Fig. 5a). The retained bicarbonate then spills over by filtration into the proximal tubular lumen where under the influence of hypokalemia it undergoes greater reabsorption. Less bicarbonate reaches the distal nephron, so that more sodium absorption is associated with the generation of new bicarbonate rather than the absorption of filtered bicarbonate. In this model, hypokalemia is critical to maintain the metabolic alkalosis of hyperaldosteronism, and potassium repletion can treat the alkalosis $[54,55]$.

The combination of hypokalemia and hypertension should raise the suspicion of a disorder in the principal cell of the collecting duct. The differential diagnosis includes a primary increase in the epithelial sodium channel as in Liddle's syndrome, increased function of the aldosterone receptor in the principal cell which in turn could be due to an activating mutation, or inactivation of the enzyme 11- $\beta$ hydroxysteroid dehydrogenase which converts cortisol to inactive cortisone (Fig. 4). A high cortisol to cortisone ratio in the urine would be suggestive of this mechanism which can be seen in patients who take excessive quantities of licorice or have a mutation in the enzyme itself (apparent mineralocorticoid excess syndrome). Cushing syndrome and ectopic secretion of ACTH are other considerations. In these causes, one would expect aldosterone levels to be low due to the volume expansion and low renin. If aldosterone levels are high, there could be an adrenal tumor leading to aldosterone secretion, but the volume expansion would still be associated with a low renin. If the renin is elevated with the increased aldosterone, then the 


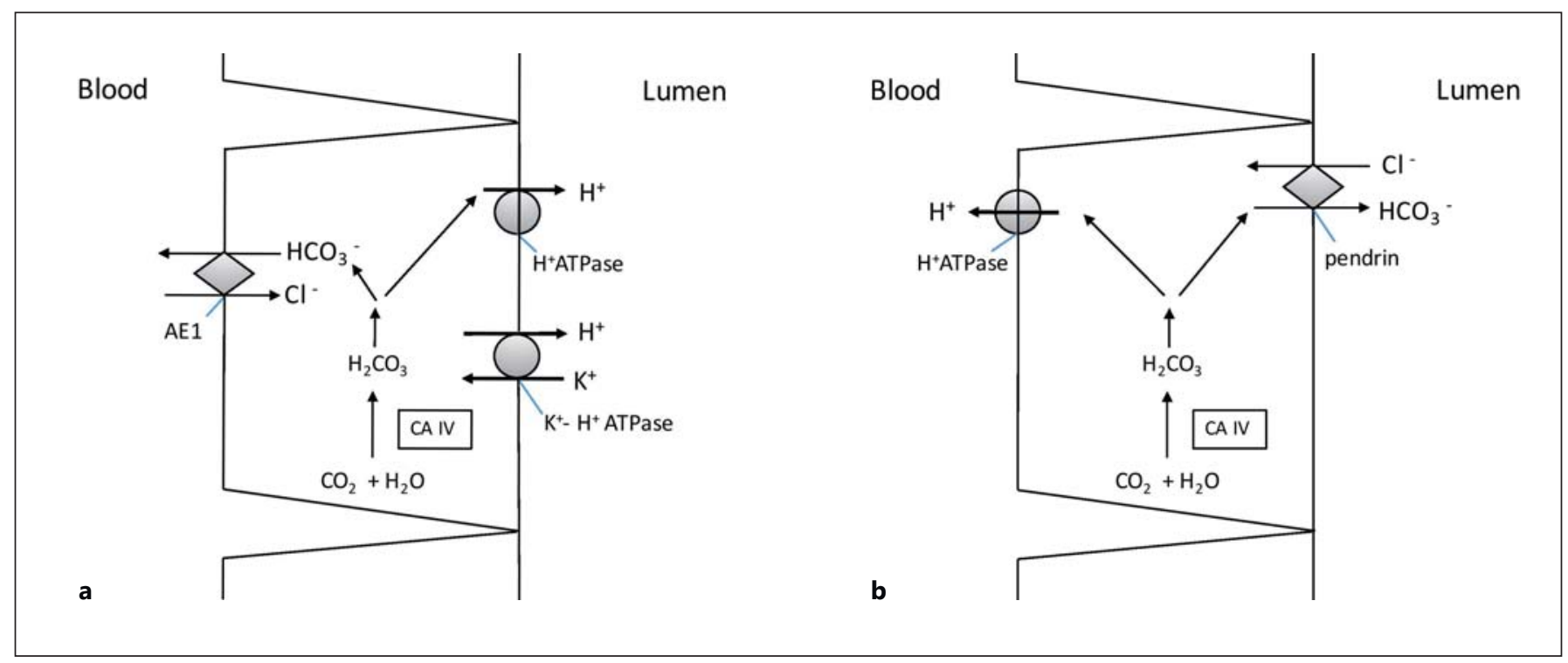

Fig. 5. a Type A (acid-secreting) intercalated cell. $\mathrm{K}^{+}-\mathrm{H}^{+}$ATPase in type A intercalated cells couples $\mathrm{K}^{+}$reabsorption with $\mathrm{H}^{+}$secretion. The exact contribution of $\mathrm{H}^{+}$ATPase vs. $\mathrm{K}^{+}-\mathrm{H}^{+}$ATPase varies in different conditions. Distal (type 1) renal tubular acidosis may be caused by gene mutations in $\mathrm{Cl}^{-} / \mathrm{HCO}_{3}{ }^{-}$exchanger (anion

source of this syndrome is the kidney, and possibilities include unilateral renal artery stenosis and renin-secreting tumors $[56,57]$.

\section{Hyperchloremic Acidosis (Table 3)}

In contrast to the above syndromes of metabolic alkalosis, one could view the opposite case of metabolic acidosis due to intestinal losses, renal losses, or adrenal disorders. For example, a patient with an ileostomy losing large quantities of alkaline small bowel contents containing sodium and bicarbonate will develop metabolic acidosis. Because the blood bicarbonate concentration is decreased and less chloride is lost, the patient will have a hyperchloremic metabolic acidosis. Large bowel losses may also contain bicarbonate salts and cause a similar acid-base disturbance. One would expect volume depletion and stimulation of the renin-angiotensin aldosterone system. In this case, the kidney will excrete more chloride by reabsorbing less of the filtered load due to high chloride in the interstitial fluid. Because ammonia production is increased in acidosis, the kidney can excrete ammonium chloride and hold on to sodium and potassium so that ammonium production in this scenario can be viewed as means to preserve the important cations for volume and potassium balance.

Perspectives in Acid-Base Balance exchanger 1, AE1). b Type B ( $\mathrm{HCO}_{3}{ }^{-}$-secreting) intercalated cell. Decreased function of pendrin, the $\mathrm{Cl}^{-} / \mathrm{HCO}_{3}{ }^{-}$exchanger in type $\mathrm{B}$ intercalated cells, is a cause of chloride-wasting metabolic alkalosis.

The kidney could also be a source of bicarbonate loss as is the case with use of certain diuretics like carbonic anhydrase inhibitors and renal tubular acidosis (Fig. 1a) (Table 6).

Again, because of the loss of cations sodium and potassium with bicarbonate instead of chloride, a hyperchloremic acidosis will develop. The urinary electrolytes will demonstrate a charge gap with sodium plus potassium minus chloride being a positive number [58]. Should the charge gap be negative, an indication of ammonium chloride excretion, then losses of bicarbonate are extrarenal. There are channelopathies that cause metabolic acidosis with hypertension including mutations activating the thiazide-sensitive sodium chloride cotransporter.

Other acidotic disorders are associated with hyperkalemia and suggest collecting duct dysfunction. In this case, thinking again of the principal cell, one would consider a decreased function of the epithelial sodium channel, a condition known as pseudo-hypoaldosteronism, or decreased function of the aldosterone receptor usually through aldosterone antagonists. In these cases, one would expect an elevation in renin and aldosterone. However, if aldosterone levels are low, one should consider adrenal or aldosterone deficiency, in which case renin levels should be very high due to the salt wasting-induced 
Table 6. Major causes of renal tubular acidosis

Hypokalemic distal (type 1) RTA

Hereditary

$\mathrm{H}^{+}$-ATPase gene mutations

$\mathrm{Cl}^{-} / \mathrm{HCO}_{3}{ }^{-}$exchanger (AE1) gene mutations

Carbonic anhydrase type II deficiency

Genetic

Sickle cell disease, Fabry's disease, Wilson's disease, medullary cystic kidneys, paroxysmal nocturnal hemoglobinuria

Autoimmune

Systemic lupus erythematosus, Sjögren's syndrome, rheumatoid arthritis

Drugs

Amphotericin B, ifosfamide, lithium, cisplatin, aminoglycosides

Nephrocalcinosis and hypercalcemic disorders

Hyperparathyroidism, vitamin D intoxication, sarcoidosis

Tubulointerstitial diseases

Acute tubulointerstitial nephritis, reflux nephropathy

Multiple myeloma and amyloidosis

Proximal (type 2) RTA

Hereditary

$\mathrm{Na} / \mathrm{HCO}_{3}{ }^{-}$cotransporter gene mutations

Carbonic anhydrase type II deficiency

Generalized proximal tubular dysfunction

Genetic: cystinosis, galactosemia, glycogen storage disease (glucose-6-phosphatase deficiency), Wilson's disease

Hormonal: hyperparathyroidism, vitamin D deficiency

Drugs: ifosfamide, tenofovir, aminoglycosides

Heavy metals: lead, mercury, copper, cobalt

Multiple myeloma, amyloidosis

Sjögren's syndrome

Renal transplantation

Hyperkalemic (type 4) RTA

Hyporeninemic hypoaldosteronism

Renal insufficiency: diabetes nephropathy, chronic interstitial nephritis

Drugs: nonsteroidal anti-inflammatory agents, calcineurin inhibitors (tacrolimus, cyclosporine)

Decreased aldosterone production

Inherited disorders: congenital hypoaldosteronism (congenital adrenal hyperplasia), pseudohypoaldosteronism type II (Gordon syndrome)

Drugs: angiotensin-converting enzyme inhibitors, angiotensin II receptor blockers, direct renin inhibitors, heparin, trimethoprim

Adrenal insufficiency

Aldosterone resistance

Inherited disorder: pseudohypoaldosteronism type I

Drugs: inhibition of the epithelial sodium channel (ENaC): amiloride, triamterene, trimethoprim, pentamidine, potassium-sparing diuretics

volume depletion. If renin levels are instead low, then hyporenin-hypoaldosteronism exists and the differential diagnosis includes renin inhibitors, nonsteroidal anti-inflammatory agents, and diseases affecting tubular function. When hypertension is present, an increased chloride reabsorptive mechanism should be considered such as increased function of the sodium-chloride cotransporter [59].
In summary, disorders of acid-base involve the complex interplay of many organ systems including brain, lungs, kidney, and liver. The mechanisms of compensation are dependent on adequate function of these organs. Compensations for brain disorders are more complete, while limitations exist for most systemic disorders. However, some of the limitations on compensations are helpful to survival, in that preservation of oxygenation, en- 
ergy balance, cognition, electrolyte, and fluid balance are connected mechanistically. Many constructs are helpful to understand acid-base, but these models are not mutually exclusive. Electroneutrality and the close interconnection between electrolyte and acid-base balance are important concepts to apply in acid-base diagnoses. All models have complexity and shortcuts that can help in practice. There is no reason to dismiss any of the present constructs, and there is benefit in a combined approach. Understanding the content and volume of all fluid inputs and outputs will assist in establishing cause and proper treatment in each case.

\section{Conflict of Interest Statement}

The authors have no conflicts of interest.

\section{References}

1 Finkel KW, Dubose TF: Metabolic acidosis; in Dubose TJ, Hamm L (eds): Acid-Base and Electrolyte Disorders: A Companion to Brenner \& Rector's The Kidney. Philadelphia, Elsevier Saunders, 2002.

2 Davison D, Segal MB: Acid-Base Relations in the Central Nervous System. Boca Raton, CRC Press, 1996.

3 Seifter JL: Acid-base disorders; in Goldman L, Schafer AI (eds): Goldman's Cecil Medicine, ed 25. Philadelphia, Saunders Elsevier, 2016.

4 Christensen MS: Acid-base changes in cerebrospinal fluid and blood, and blood volume changes following prolonged hyperventilation in man. Br J Anaesth 1974;46:348-357.

5 Mitchell RA, Loeschcke HH, Massion WH, Severinghaus JW: Respiratory responses mediated through superficial chemosensitive areas on the medulla. J Appl Physiol 1963;18: 523-533.

6 Saunders NR, Dreifuss JJ, Dziegielewska KM, et al: The rights and wrongs of blood-brain barrier permeability studies: a walk through 100 years of history. Front Neurosci 2014;8: 404.

7 Yoon SH, Zuccarello M, Rapoport RM: $\mathrm{pCO}(2)$ and $\mathrm{pH}$ regulation of cerebral blood flow. Front Physiol 2012;3;365.

8 Haddad SH, Arabi YM: Critical care management of severe traumatic brain injury in adults. Scand J Trauma Resusc Emerg Med 2012;20:12.

9 Bak LK, Schousboe A, Waagepetersen HS: The glutamate/GABA-glutamine cycle: aspects of transport, neurotransmitter homeostasis and ammonia transfer. J Neurochem 2006;98:641-653.

10 Oliver J, Bourke E: Adaptations in urea ammonium excretion in metabolic acidosis in the rat: a reinterpretation. Clin Sci Mol Med Suppl 1975;48:515-510.

11 Wanders RJ, Meijer AJ, Groen AK, Tager JM: Bicarbonate and the pathway of glutamate oxidation in isolated rat-liver mitochondria. Eur J Biochem 1983;133:245-54.

12 Shear L, Kleinerman J, Gabuzda GJ: Renal failure in patients with cirrhosis of the liver. I. Clinical and pathologic characteristics. Am J Med 1965;39:184-198.

Perspectives in Acid-Base Balance
13 Cohen JJ, Schwartz WB: Evaluation of acidbase equilibrium in pulmonary insufficiency. An approach to a diagnostic dilemma. Am J Med 1966;41:163-167.

14 Madias NE, Schwartz WB, Cohen JJ: The maladaptive renal response to secondary hypocapnia during chronic $\mathrm{HCl}$ acidosis in the dog. J Clin Invest 1977;60:1393-1401.

15 Albert MS, Dell RB, Winters RW: Quantitative displacement of acid-base equilibrium in metabolic acidosis. Ann Intern Med 1967;66: 312-322.

16 Javaheri S, Shore NS, Rose B, Kazemi H: Compensatory hypoventilation in metabolic alkalosis. Chest 1982;81:296-301.

17 Javaheri S, Kazemi H: Metabolic alkalosis and hypoventilation in humans. Am Rev Respir Dis 1987;136:1011-1016.

18 Brackett NC Jr, Cohen JJ, Schwartz WB: Carbon dioxide titration curve of normal man effect of increasing degrees of acute hypercapnia on acid-base equilibrium. $\mathrm{N}$ Engl J Med 1965;272:6-12.

19 van Ypersele de Strihou C, Brasseur L, De Coninck J: The carbon dioxide response curve for chronic hypercapnia in man. N Engl J Med 1966;275:117-122.

20 Arbus GS, Herbert LA, Levesque PR, Etsten BE, Schwartz WB: Characterization and clinical application of the "significance band" for acute respiratory alkalosis. N Engl J Med 1969;280:117-123.

21 Gennari FJ, Goldstein MB, Schwartz WB: The nature of the renal adaptation to chronic hypocapnia. J Clin Invest 1972;51:1722-1730.

22 Krapf R, Beeler I, Hertner D, Hulter HN: Chronic respiratory alkalosis. The effect of sustained hyperventilation on renal regulation of acid-base equilibrium. N Engl J Med 1991;324:1394-1401.

23 Johnson SK, Naidu RK, Ostopowicz RC, et al: Adolf Kussmaul: distinguished clinician and medical pioneer. Clin Med Res 2009;7:107112.

24 Galla JH: Metabolic alkalosis. J Am Soc Nephrol 2000;11:369-375.

25 Kiening KL, Hartl R, Unterberg AW, Schneider $\mathrm{GH}$, Bardt T, Lanksch WR: Brain tissue $\mathrm{pO}_{2}-$ monitoring in comatose patients: implications for therapy. Neurol Res 1997;19:233-240.
26 Santella RN, Maddox DA, Gennari FJ: Delivery dependence of early proximal bicarbonate reabsorption in the rat in respiratory acidosis and alkalosis. J Clin Invest 1991;87:631-638.

27 Gallagher TJ: Metabolic alkalosis complicating weaning from mechanical ventilation. South Med J 1979;72:786-787.

28 Lolekha PH, Lolekha S: Value of the anion gap in clinical diagnosis and laboratory evaluation. Clin Chem 1983;29:279-283.

29 Mehta AN, Emmett JB, Emmett M: GOLD MARK: an anion gap mnemonic for the 21st century. Lancet 2008;372:892.

30 Batlle DC, Hizon M, Cohen E, Gutterman C, Gupta R: The use of the urinary anion gap in the diagnosis of hyperchloremic metabolic acidosis. N Engl J Med 1988;318:594-599.

31 Berend K, de Vries AP, Gans RO: Physiological approach to assessment of acid-base disturbances. N Engl J Med 2014;371:14341445.

32 Sabatini S, Kurtzman NA: Bicarbonate therapy in severe metabolic acidosis. J Am Soc Nephrol 2009;20:692-695.

33 Sullivan WJ, Dorman PJ: The renal response to chronic respiratory acidosis. J Clin Invest 1955;34:268-276.

34 Barker ES, Singer RB, Elkinton JR, Clark JK: The renal response in man to acute experimental respiratory alkalosis and acidosis. J Clin Invest 1957;36:515-529.

35 Levitin H, Branscome W, Epstein FH: The pathogenesis of hypochloremia in respiratory acidosis. J Clin Invest 1958;37:1667-1675.

36 Schwartz WB, Falbriard A, Lemieux G: The kinetics of bicarbonate reabsorption during acute respiratory acidosis. J Clin Invest 1959; 38:939-944.

37 Gamble JL Jr: Sodium and chloride and acidbase physiology. Bull Johns Hopkins Hosp 1960;107:247-254.

38 Ramadoss J, Stewart RH, Cudd TA: Acute renal response to rapid onset respiratory acidosis. Can J Physiol Pharmacol 2011;89:227231.

39 Stewart PA: Modern quantitative acid-base chemistry. Can J Physiol Pharmacology 1983; 61:1444-1461. 
40 Kurtz I, Kraut J, Ornekian V, Nguyen MK: Acid-base analysis: a critique of the Stewart and bicarbonate-centered approaches. Am J Physiol Renal Physiol 2008;294:F1009_ F1031.

41 McAuliffe JJ, Lind LJ, Leith DE, Fencl V: Hypoproteinemic alkalosis. Am J Med 1986;81: 86-90.

42 Chawla LS, Shih S, Davison D, Junker C, Seneff MG: Anion gap, anion gap corrected for albumin, base deficit and unmeasured anions in critically ill patients: implications on the assessment of metabolic acidosis and the diagnosis of hyperlactatemia. BMC Emerg Med 2008;8:18.

43 Kassirer JP, Appleton FM, Chazan JA, Schwartz WB: Aldosterone in metabolic alkalosis. J Clin Invest 1967;46:1558-1571.

44 Take C, Ikeda K, Kurasawa T, Kurokawa K: Increased chloride reabsorption as an inherited renal tubular defect in familial type II pseudohypoaldosteronism. N Engl J Med 1991;324:472-476.

45 Figge J, Jabor A, Kazda A, Fencl V: Anion gap and hypoalbuminemia. Crit Care Med 1998; 26:1807-1810.

46 Kraut JA, Nagami GT: The serum anion gap in the evaluation of acid-base disorders: what are its limitations and can its effectiveness be improved? Clin J Am Soc Nephrol 2013;8: 2018-2024.
47 Schwartz WB, Jenson RL, Relman AS: Acidification of the urine and increased ammonium excretion without change in acid-base equilibrium: sodium reabsorption as a stimulus to the acidifying process. J Clin Invest 1955;34:673-680

48 Reddy P, Mooradian AD: Clinical utility of anion gap in deciphering acid-base disorders. Int J Clin Pract 2009;63:1516-1525.

49 Eaton DC, Becchetti A, Ma H, Ling BN: Renal sodium channels: regulation and single channel properties. Kidney Int 1995;48:941-949.

50 Mersin SS, Ramelli GP, Laux-End R, Bianchetti MG: Urinary chloride excretion distinguishes between renal and extrarenal metabolic alkalosis. Eur J Pediatr 1995; 154:979982.

51 Wang XY, Masilamani S, Nielsen J, et al: The renal thiazide-sensitive $\mathrm{Na}-\mathrm{Cl}$ cotransporter as mediator of the aldosterone-escape phenomenon. J Clin Invest 2001;108:215-222.

52 Dorrance AM: Interfering with mineralocorticoid receptor activation: the past, present, and future. F1000Prime Rep 2014;6:61.
53 Kapoor A, Morris T, Rebello R: Guidelines for the management of the incidentally discovered adrenal mass. Can Urol Assoc J 2011; 5: 241-247.

54 Moviat M, Pickkers P, van der Voort PH, van der Hoeven JG: Acetazolamide-mediated decrease in strong ion difference accounts for the correction of metabolic alkalosis in critically ill patients. Crit Care 2006;10:R14.

55 Cohn JN, Kowey PR, Whelton PK, Prisant LM: New guidelines for potassium replacement in clinical practice: a contemporary review by the National Council on Potassium in Clinical Practice. Arch Intern Med 2000;160: 2429-2436.

56 Brewster UC, Perazella MA: The renin-angiotensin-aldosterone system and the kidney: effects on kidney disease. Am J Med 2004;116: 263-272.

57 Atlas SA: The renin-angiotensin aldosterone system: pathophysiological role and pharmacologic inhibition. J Manag Care Pharm 2007; 13:9-20.

58 Kunau RT Jr: The influence of the carbonic anhydrase inhibitor, benzolamide (CL11,366 ), on the reabsorption of chloride, sodium, and bicarbonate in the proximal tubule of the rat. J Clin Invest 1972;51:294-306.

59 Pratt JH: Central role for $\mathrm{ENaC}$ in development of hypertension. J Am Soc Nephrol $2005 ; 16: 3154-3159$. 